\title{
Preparing Mn-CoO-Supported Pyrolysis Coke Catalyst with Plasma and its Application in the SCO Denitration Process
}

\author{
Zhang Lei ${ }^{1 *}$, Chen Jihao ${ }^{1}$, Lei Zhang ${ }^{2}$, Sha Xiangling ${ }^{3}$, Li Yonghui ${ }^{2}$, Fan Min ${ }^{1}$ \\ ${ }^{1}$ School of Geology and Environment, Xi' an University of Science and Technology, Xi'an, China \\ ${ }^{2}$ China National Heavy Machinery Research Institute Co. Ltd, Xi'an, China \\ ${ }^{3}$ Shandong Baichuan Tongchuang Energy Co. Ltd, Jinan, China
}

Received: 22 April 2018

Accepted: 14 August 2018

\begin{abstract}
In order to reduce nitrogen oxides in the flue gas and improve the quality of the atmosphere, an $\mathrm{Mn}-\mathrm{CoO}-$-supported pyrolysis coke catalyst was prepared using equivalent-volume impregnation, and then its denitration efficiency was studied in a simulated flue gas denitrification device in the paper. The composition of the flue gas was a mixture of $\mathrm{N}_{2}, \mathrm{O}_{2}, \mathrm{NO}$, and $\mathrm{SO}_{2}$. Good denitration catalysts were prepared by changing plasma modification time and modified power, $\mathrm{MnO}$ load and $\mathrm{Mn}-\mathrm{CoO}$ load. The denitration mechanism of the catalyst was analyzed by XRD, BET and SEM. The results are: optimal modified power in the plasma system was $60 \mathrm{~W}$, and the best modified time in plasma system was 3min; after being modified by plasma, the denitration efficiency of catalysts were significantly higher than conventional calcination catalyst; among catalysts with different $\mathrm{CoO}$ loadings $(5 \%, 8 \%$, $10 \%$ ), $8 \% \mathrm{CoO}$ loading had the best denitration efficiency, the best denitration efficiency reached $98 \%$ and time of higher denitration efficiency had also been extended a lot; Mn-CoO-supported catalysts had a certain $\mathrm{SO}_{2}$-resistance, and the denitration efficiency of $\mathrm{Mn}$-CoO-supported catalyst $>\mathrm{MnO} /$ supported catalyst > un-supported catalyst.
\end{abstract}

Keywords: equivalent-volume impregnation, plasma modified, supported catalyst, denitration

\section{Introduction}

Coal combustion produces a lot of nitrogen oxides, and they are very harmful to human health and environmental pollution [1]. Nowadays, the technology of nitrogen oxide removal is mainly selective catalytic reduction (SCR) technology [2]. SCR is when $\mathrm{NH}_{3}$ is

*e-mail: 136750178@qq.com added to the flue gas system, and then nitrogen oxides are reduced to $\mathrm{N}_{2}$ under the action of a catalyst. However, SCR technology requires very high temperature, and energy consumption is relatively large [3]. SCR is a relatively mature technology. But a large amount of $\mathrm{NH}_{3}$ is needed, the cost is large, and the reduction products have no reusable value. $\mathrm{NH}_{3}$ has played a role in the formation of PM2.5, and SCR has the problem of $\mathrm{NH}_{3}$ escaping [4]. Therefore, in the process of treatment, we must strictly control $\mathrm{NH}_{3}$ and avoid secondary pollution. 
Selective catalytic oxidation (SCO) is when NO is oxidized to $\mathrm{NO}_{2}$ by utilizing $\mathrm{O}_{2}$ in flue gas and the reaction can be carried out at low temperature [5-7]; therefore, energy consumption is smaller. SCO can make up for the defects of SCR. Therefore, SCO can be well applied in flue gas denitration [8]. So it is a highly competitive technology of flue gas denitration.

At present, there are two mechanisms of oxidation. The mechanisms of SCO denitration are:

The first mechanism:

$$
\mathrm{NO}+\mathrm{O}_{2} \rightarrow \mathrm{NO}_{3}, \mathrm{NO}_{3}+\mathrm{NO} \rightarrow 2 \mathrm{NO}_{2}
$$

The second mechanism:

$$
2 \mathrm{NO} \rightarrow(\mathrm{NO})_{2},(\mathrm{NO})_{2}+\mathrm{O}_{2} \rightarrow 2 \mathrm{NO}_{2}
$$

There is a competitive relationship between the two reactions. Since the reaction of NO polymerization of the second mechanism is exothermic, the second mechanism occupies an advantage at low temperature [9].

However, SCO needs an economical and efficient catalyst. Currently, molecular sieves [10], active carbon [11], metal oxides [12], and noble metals [13] are common catalyst materials. Molecular sieves as catalysts are mostly used in reduction and decomposition processes [14], but are not suitable for SCO. Active carbon has a large surface area and special hole structure, and the price of active carbon is cheap. But the shortcoming of active carbon is that it has low activity at high temperature, so it is not a good catalyst in the process of flue gas denitration. The noble metal catalyst has good activity and it can also meet the requirements under high temperature conditions. But the expensive price limits its wide range of application and promotion [15]. However, the supported metal catalyst is a good catalyst.

Pyrolysis coke is a solid residue produced after coal pyrolysis [16]. Pyrolysis coke is difficult to have a good follow-up value. However, it has a rich pore structure and it contains many oxygen-containing functional groups on the surface [17], therefore pyrolysis coke itself has a good effect. Pyrolysis coke can adsorb NO and other gaseous pollutants, which is a good carrier of adsorbent and catalyst. A catalyst prepared by pyrolysis coke realizes waste utilization and it also has less environmental pollution. Pyrolysis coke is impregnated with the solution, metal active component is loaded on the carrier, and the activity of the catalyst is greatly improved. Manganese oxide and cobalt oxide are good active components and can be loaded onto the carrier by impregnation. By roasting, an inexpensive, low energy and stable catalyst is prepared [18].

The preparation process of a traditional catalyst is calcined in a muffle furnace. This process consumes high energy, and the active components are easily agglomerated. Therefore, this process affects the activity of a catalyst. The preparation process of the catalyst prepared by plasma modification not only reduces energy consumption, but it also makes the better dispersion of the active component, and obviously improves the activity [19-20]. Therefore, the catalyst prepared by plasma has a better effect.

The innovative points of this paper are as follows: pyrolysis coke is used as the carrier and is supported with a metal active component; the traditional catalyst is modified by plasma; the catalyst is applied in the SCO denitration process. Different $\mathrm{MnO}$ contents and different $\mathrm{CoO}$ contents are supported on pyrolysis coke carrier, the catalysts are modified with different powers and different time, and then the denitration efficiency is investigated in the SCO denitration process. The denitration mechanisms are obtained by the characterization analysis results of XRD, XPS, SEM and BET.

\section{Experimental}

\author{
Experimental Material \\ and Experimental Medicines
}

Experimental material is lignite and the diameter of lignite is $1 \sim 2 \mathrm{~mm}$. Pyrolysis coke is made of lignite.

Experimental medicines: manganese nitrate solution, $\mathrm{Mn}\left(\mathrm{NO}_{3}\right)_{2}$, (Tianjin Fuchen Chemical Reagent Factory, $50 \%$ purity); six cobalt nitrate hydrate, $\mathrm{Co}\left(\mathrm{NO}_{3}\right)_{2} \cdot 6 \mathrm{H}_{2} \mathrm{O}$, (Guangdong Guanghua Sci-Tech Co., Ltd. analytical purity $\geq 99 \%$ )

\section{Preparing the Catalysts \\ Preparing Pyrolysis Coke}

A certain quality of lignite particles were taken and placed into a tubular furnace. The inner diameter of the tube is $22 \mathrm{~mm}$ and the outer diameter is 26 $\mathrm{mm}$. Argon is a protective gas and the flow rate is $40 \mathrm{ml} / \mathrm{min}$. The temperature rises from $24^{\circ} \mathrm{C}$ to $750^{\circ} \mathrm{C}$, the lignite is pyrolyzed for 4 hours, then the temperature of the pyrolysis furnace drops from $750^{\circ} \mathrm{C}$ to $24^{\circ} \mathrm{C}$. The remainder is taken, which is $750^{\circ} \mathrm{C}$ pyrolysis coke.

\section{Preparation of Conventional MnO-Supported Catalyst}

Manganese nitrate solution is configured, and the $\mathrm{MnO}$ loading is $8 \% .10 \mathrm{~g}$ pyrolysis coke is impregnated with equal volume impregnation. It is statically placed for 12 hours, then placed in a drying box at $120^{\circ} \mathrm{C}$ and baked for 30 minutes. Then it is put into a muffle furnace at $450^{\circ} \mathrm{C}$. It was roasted for 4 hours. The temperature is lowered to room temperature. It is taken out, which is a conventional $8 \% \mathrm{MnO}$-supported catalyst.

\section{Preparing MnO-Supported Catalyst by Plasma Modification}

Argon gas is used as a plasma-modified gas. The gas flow is $40 \mathrm{ml} / \mathrm{min}$. 
(1) The 10 g conventional $8 \% \mathrm{MnO}$-supported catalyst is taken and put into the plasma. The modification time is 10 minutes. The modification power is $30 \mathrm{~W}, 60 \mathrm{~W}$ and $90 \mathrm{~W}$, respectively. They are $8 \% \mathrm{MnO}$-supported catalysts of different power (C30W, C60W and C90W, respectively).

(2) The 10 g conventional 8\% MnO-supported catalyst is taken and put into the plasma. The modification power is $60 \mathrm{~W}$. The modification time is 3 minutes, 10 minutes and 15 minutes, respectively. They are $8 \% \mathrm{MnO}$-supported catalysts of different times (C3T, C10T and C15T, respectively).

(3) Manganese nitrate solution is configured, and the MnO loading is $1 \%, 3 \%, 5 \%$ and $8 \%$, respectively. The conventional $1 \%, 3 \%, 5 \%$ and $8 \% \mathrm{MnO}-$ supported catalyst are prepared. The $10 \mathrm{~g}$ conventional MnO-supported catalyst is taken and put into the plasma, respectively. The modification power is $60 \mathrm{~W}$, and the modification time is 3 minutes, respectively. They are $1 \%, 3 \%, 5 \%$ and $8 \%$ MnO-supported catalyst by plasma modification $(\mathrm{C} 1, \mathrm{C} 3, \mathrm{C} 5$ and $\mathrm{C} 8$, respectively).

\section{Preparing the Mn-CoO-Supported Catalyst by Plasma Modification}

Argon gas is used as a plasma-modified gas. The gas flow is $40 \mathrm{ml} / \mathrm{min}$.

Cobalt nitrate solution is configured, and the loading amount of $\mathrm{CoO}$ is $5 \%, 8 \%$ and $10 \%$, respectively. The $10 \mathrm{~g}$ conventional $8 \% \mathrm{MnO}$-supported catalyst is impregnated with equal volume impregnation. A conventional catalyst was prepared using the same method, they are conventional 5\%,8\% and 10\% MnCoO-supported catalyst, respectively.

The $10 \mathrm{~g}$ conventional Mn-CoO-supported catalyst is taken and put into the plasma, respectively. The modification power is $60 \mathrm{~W}$. The modification time is 3 minutes. They are $5 \%, 8 \%$ and $10 \% \mathrm{Mn}-\mathrm{CoO}-$ supported catalysts (C8-5, C8-8 and C8-10, respectively).

\section{Catalyst Characterization Method}

Specific surface area (BET): The JW-BK122W type surface and pore size analyzer is used to measure the specific surface area of different types of catalysts.

$\mathrm{X}$-ray analysis (XRD): XD-3 type ray diffractometer; test parameters: voltage is $36 \mathrm{KV}$, current is $20 \mathrm{~mA}$, the target is $\mathrm{Cu}, 2 \theta / \theta$ is $10^{\circ}$ to $80^{\circ}$, and scanning speed is $10 \%$ min.

Scanning electron microscope (SEM): JSM-6460LV, working voltage $20 \mathrm{kV}$, magnification 5000 times.

$\mathrm{X}$-ray electron spectroscopy (XPS): XPS is an important tool for analyzing the surface structure and composition of an element, and it can get the composition of the test object.

\section{Experimental Device and Detection Method}

The test device is shown in Fig. 1. The device can be divided into three parts: a gas distribution system, a reaction system and a detection system. The gas distribution system consists of four cylinders: $\mathrm{N}_{2}, \mathrm{O}_{2}$, $\mathrm{NO}$, and $\mathrm{SO}_{2}$; the reaction system is mainly composed of a mass flow meter, a mixing bottle, two reaction towers and an air pipeline, the detection system is a gas collection bottle at the end, and Testo340 is used to detect nitrogen oxides.

The temperature of reaction tower $\mathrm{A}$ and reaction tower $\mathrm{B}$ is raised to $150^{\circ} \mathrm{C}$. The total gas flow is $1000 \mathrm{ml} / \mathrm{min}$; the NO content is $450 \mathrm{ppm}$ and the flow is $18 \mathrm{ml} / \mathrm{min}$; the $\mathrm{O}_{2}$ content is $6 \%$ and the flow is $60 \mathrm{ml} / \mathrm{min}$; the rest is filled with $\mathrm{N}_{2} . \mathrm{SO}_{2}$ is increased during the sulphur resistance test. Its content is $0.2 \%$ and the flow is $50 \mathrm{ml} / \mathrm{min}$.

In each experiment, the $10 \mathrm{~g}$ catalyst is placed in reaction tower, and the changes of NO are detected by Testo340 (German production) and recorded. Reaction tower $\mathrm{A}$ and reaction tower $\mathrm{B}$ are in series.

The denitration efficiency of $750^{\circ} \mathrm{C}$ pyrolysis coke, conventional $8 \% \mathrm{MnO}$-supported catalyst,

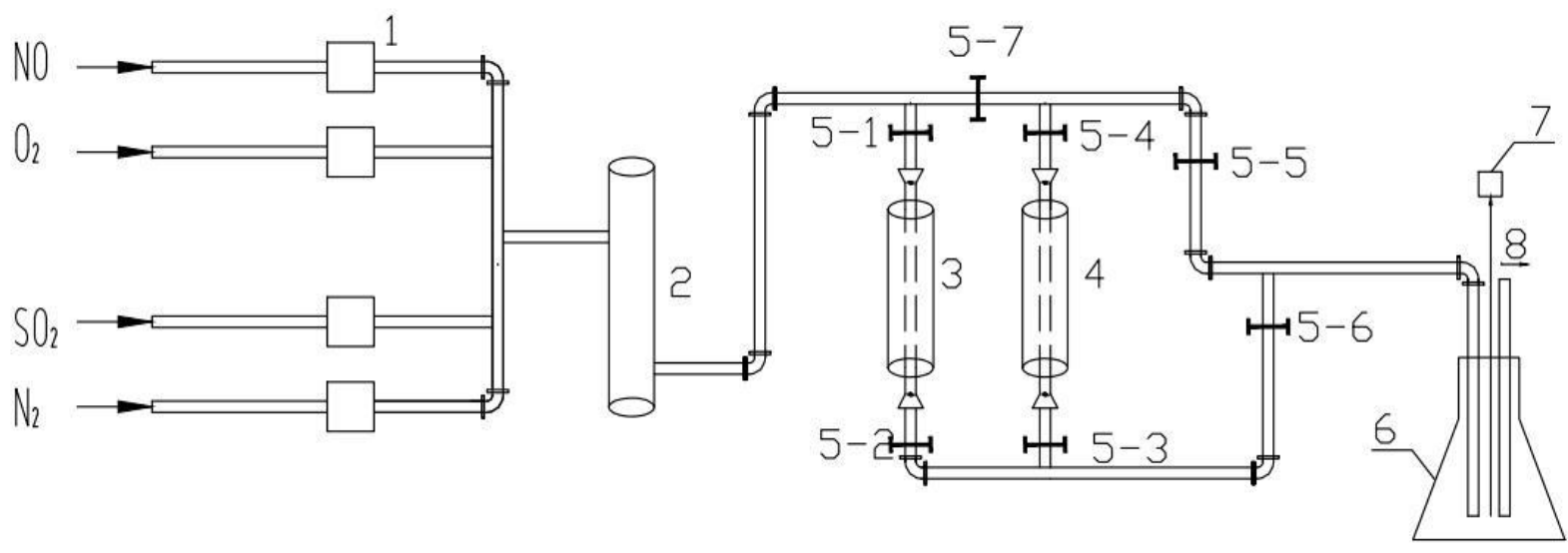

Fig. 1. Test device

1. flowmeter 2. mixed gas cylinders 3. reaction tower A 4 . reaction tower B 5-1 to 5-7 valve control 6. test the cylinder 7. condensing unit 8. absorb the gas. 
$8 \% \mathrm{MnO}$-supported catalysts of different power, $8 \% \mathrm{MnO}$-supported catalysts of different time, $\mathrm{MnO}$-supported catalyst by plasma modification and $\mathrm{Mn}-\mathrm{CoO}$-supported catalysts are respectively tested. The denitration efficiency of different types of catalysts are discussed.

$750^{\circ} \mathrm{C}$ pyrolysis coke, $\mathrm{MnO}$-supported catalyst by plasma modification and $\mathrm{Mn}-\mathrm{CoO}$-supported catalysts are placed in the reaction tower, and $\mathrm{SO}_{2}$ is pumped into the reactor. The $\mathrm{SO}_{2}$-resistance of the catalysts is detected.

\section{Results and Discussion}

\section{Denitration Efficiency of MnO-Supported Catalyst}

\section{Denitration Efficiency of 8\%MnO-Supported Catalysts of Different Power}

Fig. 2 shows the effect of different powers on denitration efficiency. Most of the supported catalysts complete the catalytic process through the cooperation of metal and carriers. During the reaction process there are frequent material exchanges and energy transfers between the metal and the carrier, this process takes place through the interface between the metal and the carrier, therefore the interfacial properties greatly affect catalytic efficiency. In this experiment, argon plasma modification is adopted to change the interaction between metal and carrier. And it can be seen that the denitration efficiency of the catalyst increases and then decreases with the increase of the modified power. The power increases from $30 \mathrm{~W}$ to $60 \mathrm{~W}$, and the denitration efficiency of the catalyst is improved. There are several reasons for this. The modification has no significant effect on the dispersibility of the nitrate material, the metal material migrates from the channel of pyrolysis coke to external surface of pyrolysis coke with the increase of the modified power, and then the metal particles are firmly fixed on the surface and are prevented from migrating and agglomerating during the subsequent roasting process. At the same time, the

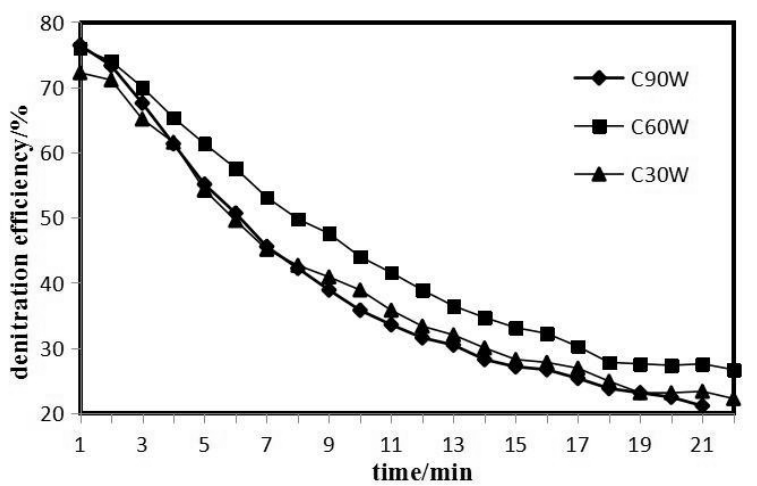

Fig. 2. Effect of different modified power of plasma on denitration efficiency.

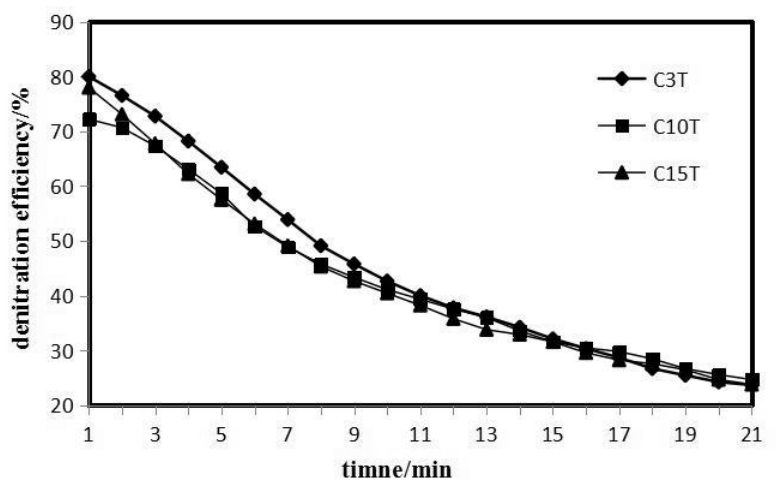

Fig. 3. Effect of different modified time of plasma on denitration efficiency.

metal particles are prevented from leaving the surface of the carrier during the subsequent roasting process, the interaction between the metal and the carrier is improved, and the denitration efficiency of the catalyst is increased. When the power is $90 \mathrm{~W}$, denitration efficiency decreases. The reasons are: the power is too large, the surface defects of the pyrolysis coke are repaired, and the dispersivity of active metal on the surface of pyrolysis coke is reduced. Therefore, the denitration efficiency of the catalyst decreases. So, the $60 \mathrm{~W}$ modified catalyst is the best for denitration.

For each catalyst denitration efficiency is reduced. The reason is that the amount of gas is always very sufficient and the amount of the catalyst is very small, and the activity of the catalyst slowly decreases with the denitration reaction.

\section{Denitration Efficiency of 8\% MnO-Supported Catalysts of Different Time}

Fig. 3 shows that denitration efficiency decreases with the increase of time of reaction. The denitration effect of $\mathrm{C} 3 \mathrm{~T}$ is the best in the first 10 minutes, and the denitration effect of C3T, C10T and C15T is basically the same after 10 minutes. So 3 minutes is the best modification. The reason are: the metal particles are thinned by plasma treatment and migrate from the pore of pyrolysis coke to the outer surface, and the dispersivity of the active metal is increased; however, with the growth of plasma modification time, the surface defects of pyrolysis coke are repaired, the pore structure of pyrolysis coke is destroyed, and the dispersivity of active metal on the surface of pyrolysis coke is reduced so that denitration efficiency decreases. Therefore, the catalyst modified for 3 minutes has the best effect on denitration efficiency.

\section{Denitration Effect of MnO-Supported Catalyst of Different Content}

Fig. 4 shows the effect of different $\mathrm{MnO}$ contents on denitration efficiency. With the increase of $\mathrm{MnO}$ 


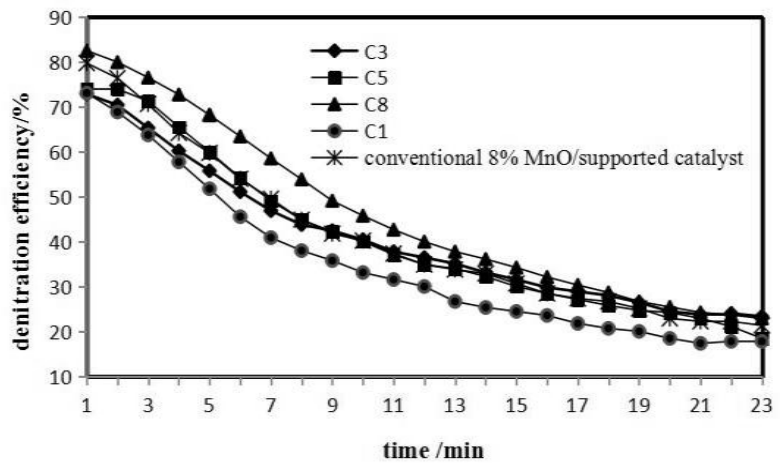

Fig. 4. Effect of different $\mathrm{MnO}$ content on denitration efficiency.

content, denitration efficiency is increasing. The denitration efficiency of $\mathrm{C} 5$ and the conventional $8 \%$ MnO-supported catalyst is similar, and that of the conventional $8 \%$ MnO-supported catalyst and C3 is similar. Therefore, it can be concluded that the activity of the catalyst is obviously increased after the plasma modification, and the efficiency of the plasma modification is equal to the increase of the metal content. The surface-free radical was formed on the surface by plasma modification, which enhanced the polarity. The dispersion of active components is increased, and the relationship between active components and carriers is enhanced so that denitration efficiency of plasmamodified catalyst is improved.

\section{Denitration Efficiency of Mn-CoO-Supported Catalyst by Plasma Modification}

The $10 \mathrm{~g}$ catalyst is placed in a reaction tower. The temperature of reaction towers is raised to $150^{\circ} \mathrm{C}$. The total gas flow is $1000 \mathrm{ml} / \mathrm{min}$; the NO content is $450 \mathrm{ppm}$ and the flow is $18 \mathrm{ml} / \mathrm{min}$; the $\mathrm{O}_{2}$ content is $6 \%$ and the flow is $60 \mathrm{ml} / \mathrm{min}$, the rest is filled with $\mathrm{N}_{2}$. $\mathrm{SO}_{2}$ is increased during the sulphur resistance test. Its content is $0.2 \%$ and the flow is $50 \mathrm{ml} / \mathrm{min}$.

Fig. 5 shows the effect of different $\mathrm{CoO}$ content on denitration efficiency. And it can be seen that denitration efficiency increases and then decreases with the increase of $\mathrm{CoO}$ content. The reason is that $\mathrm{CoO}$ and $\mathrm{MnO}$ have a synergistic effect on the surface of the catalyst,

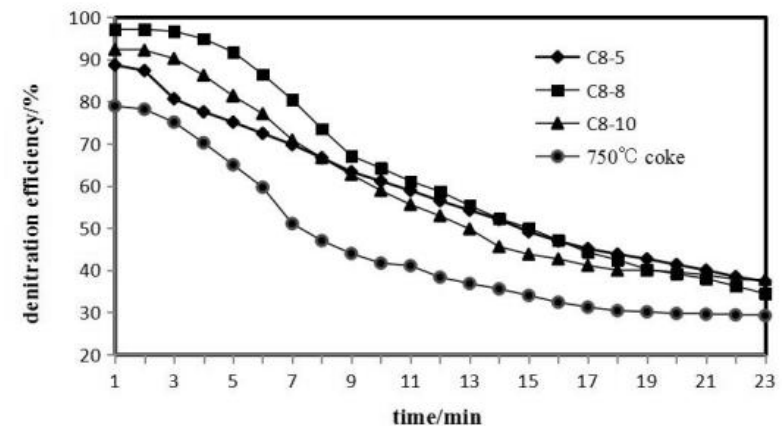

Fig. 5. Effect of different $\mathrm{CoO}$ content on denitration efficiency. which reduces the energy of $\mathrm{NO}$ oxidized to $\mathrm{NO}_{2}$, and improves the activity at low temperatures. However, when the content of $\mathrm{CoO}$ is too much, a large number of $\mathrm{CoO}$ crystals are dispersed in the pores of the pyrolysis coke, which leads to a decrease of the dispersion of $\mathrm{CoO}$ and the reduction of denitration efficiency.

When metal oxide is a non-stoichiometric compound, an N-type or P-type semiconductor is produced by introducing impurity ions or atoms. An N-type or P-type semiconductor is produced by introducing impurity ions or atoms. Impurities are distributed in metal oxide crystals in the form of atoms, ions, or groups, and exist on the surface of the crystal or at the junction of the lattice. These impurities can cause the appearance of the impurity energy level in the forbidden band of semiconductor. An N-type semiconductor is a kind of impurity semiconductor and its free electron concentration is much more than the hole concentration. Such impurities provide electronic carriers with a negative charge, which are called donor impurities or N-type impurities. In the N-type semiconductors, the free electrons are majority carriers, the holes are minority carriers, and the free electrons conduct electricity. Because the current charge of an N-type semiconductor is equal to the negative charge, N-type semiconductor is electrically neutral. Free electrons are supplied mainly by impurity atoms and the holes are created by heat. The more impurities added, the higher the concentration of free electrons and the stronger the electrical conductivity. P-type semiconductors, free electrons are minority carriers, the holes are majority carriers, and the holes conduct electricity. Because the current charge of a P-type semiconductor is equal to the negative charge, a P-type semiconductor is also electrically neutral. The holes are supplied mainly by impurity atoms and free electrons are created by heat. The more impurities added, the higher the concentration of the holes, the stronger the electrical conductivity and the higher the oxidation performance.

It can be seen from XRD that the main oxide of $\mathrm{Mn}$ is $\mathrm{MnO}_{2}$ and that of $\mathrm{Co}$ is $\mathrm{Co}_{3} \mathrm{O}_{4}$. The denitration efficiency of a bimetal-supported catalyst has been improved. The reason is that $\mathrm{MnO}_{2}$ is a P-type semiconductor that conducts electricity by the holes. When $\mathrm{Co}_{3} \mathrm{O}_{4}$ is loaded, the valence of cobalt is lower than that of manganese, acting as the main impurity.

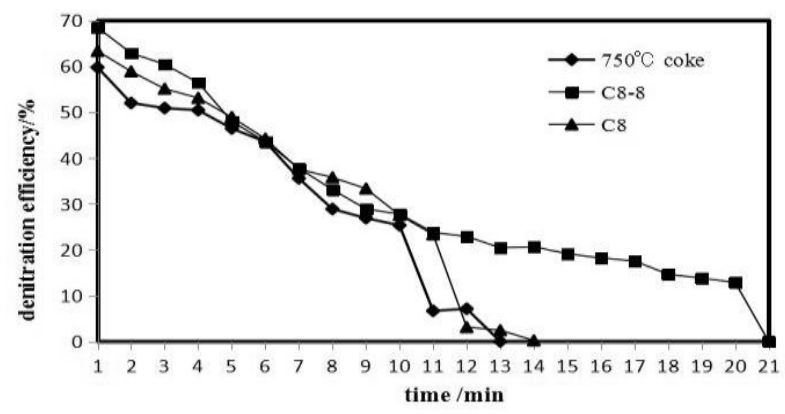

Fig. 6. $\mathrm{SO}_{2}$-resistance of the catalyst. 
a)

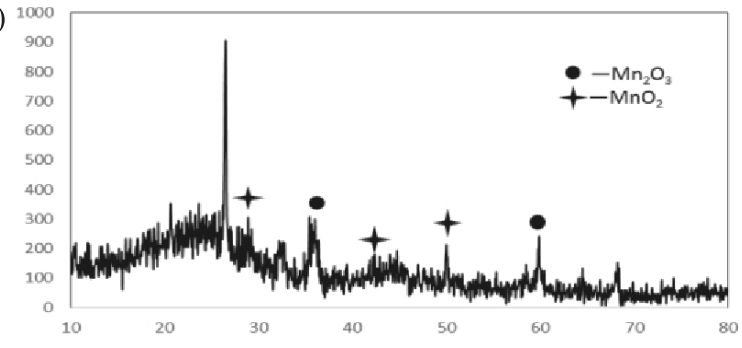

b)

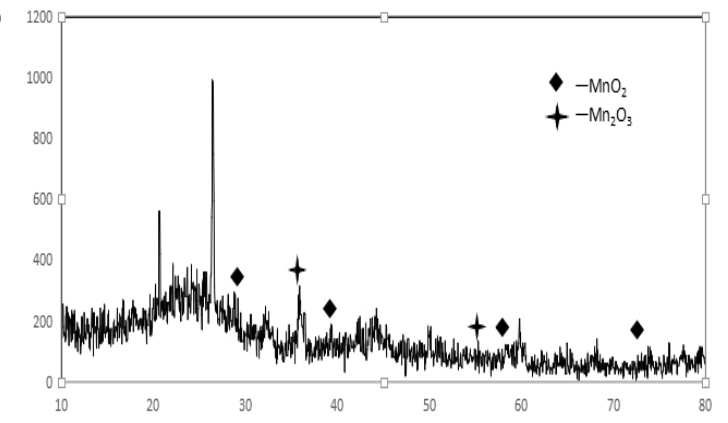

c)

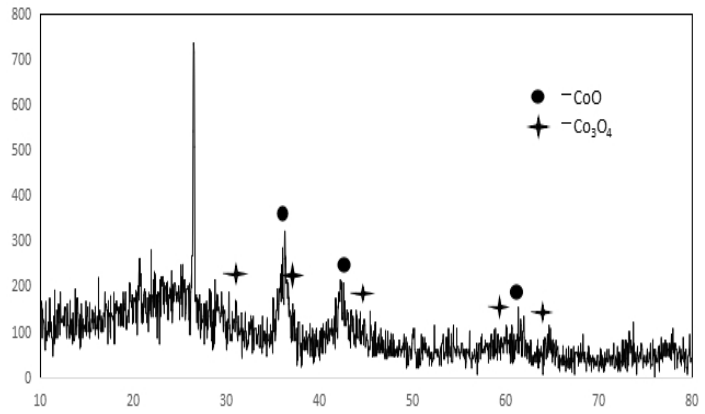

Fig. 7. XRD spectra of catalysts under different conditions: a) the conventional $8 \% \mathrm{MnO}$-supported catalyst, b) $\mathrm{C} 8$, c) $\mathrm{C} 8-10$.

The holes of $\mathrm{MnO}_{2}$ have been increased and the conductivity of P-type semiconductor $\mathrm{MnO}_{2}$ is increased. Therefore, the reactive power of the NO oxidation process is reduced and the denitration efficiency of the catalyst is improved.

\section{Experiment on $\mathrm{SO}_{2}$ Resistance of the Catalyst}

In Fig. 6, when $\mathrm{SO}_{2}$ is added, the denitration efficiency changes. Denitration efficiency was obviously reduced when $\mathrm{SO}_{2}$ was entered. The time of stabilizing denitration efficiency of $750^{\circ} \mathrm{C}$ pyrolysis coke is 10 minutes and that of $\mathrm{C} 8$ is only 11 minutes, so the performance of their $\mathrm{SO}_{2}$ resistance is poor. However, when $\mathrm{CoO}$ is added, the $\mathrm{Mn}-\mathrm{CoO}$-supported catalyst can maintain a stable denitration efficiency for about 20 minutes, which shows that the addition of $\mathrm{CoO}$ has obviously optimized the disadvantage of the poor toxicity of $\mathrm{MnO}$.

The reason is that in the reaction tower, $\mathrm{SO}_{2}$ reacts with $\mathrm{O}_{2}$, and then $\mathrm{SO}_{3}$ is generated. The $\mathrm{SO}_{3}$ reacts with the metal oxide, and the sulfate is produced. $\mathrm{SO}_{3}$ reacts with metal oxide, and the sulfate is produced. The sulfate slowly covers the surface of the catalyst and the void is blocked on the surface, thus the active sites of metal oxides are reduced, and then denitration efficiency is reduced.

At the same time, the $\mathrm{Mn}-\mathrm{CoO}$-supported catalyst has certain $\mathrm{SO}_{2}$-resistance. The relationship between $\mathrm{SO}_{3}$ and $\mathrm{SO}_{2}, \mathrm{NO}$ is competitive adsorption, and $\mathrm{SO}_{3}$ is more easily adsorbed. The adsorption site of $\mathrm{SO}_{2}$ is mainly $\mathrm{O}^{\mathrm{n}}$, the dentate sulfate is formed, and then it plays a protective role. Therefore, NO can only react with the catalyst in the form of molecular diffusion, and then the activity time is prolonged. It is inferred that the $\mathrm{Mn}-\mathrm{CoO}$-supported catalyst has good antitoxicity.

\section{Characterization of the Catalysts}

\section{XRD Characterization}

Fig. 7 shows that the main oxide of $\mathrm{Mn}$ is $\mathrm{MnO}_{2}$ and the main oxide of $\mathrm{Co}$ is $\mathrm{Co}_{3} \mathrm{O}_{4}$. It can be seen that the peak height of the manganese and cobalt spectral peak is smaller, the spectral peak is wide and flat, and then big crystals do not appear. The plasma increases well the dispersivity of active component on the surface of the carrier, the active component of the catalyst is evenly distributed and it also improves reactivity. With high denitration efficiency, the dispersion of active ingredients is good.

\section{XPS Characterization \\ XPS of $8 \%$ MnO-Supported Catalyst by Plasma Modification}

In order to further understand the energy of metal oxide on the surface of the catalyst, XPS characterization
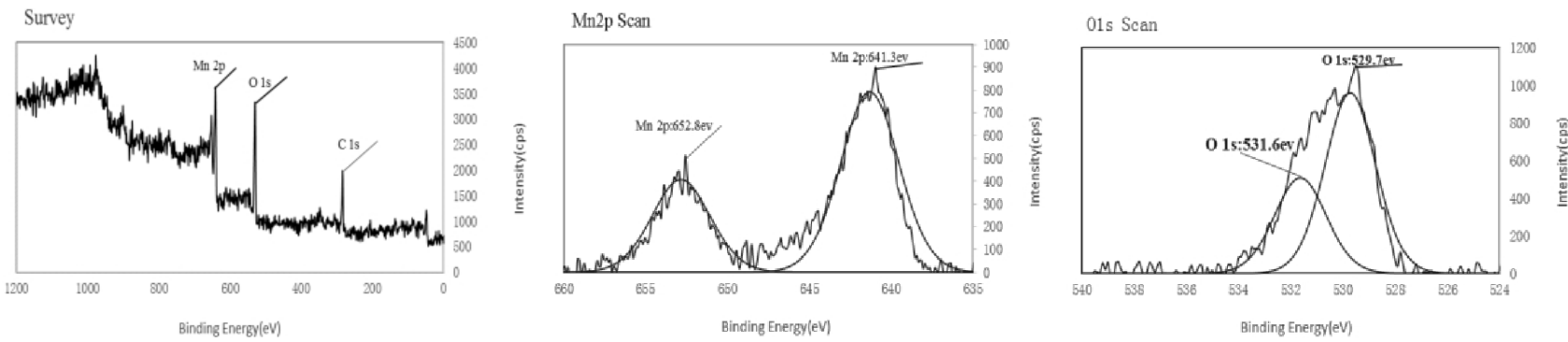

Fig. 8. XPS of $8 \%$ MnO-supported catalyst by plasma modification. 


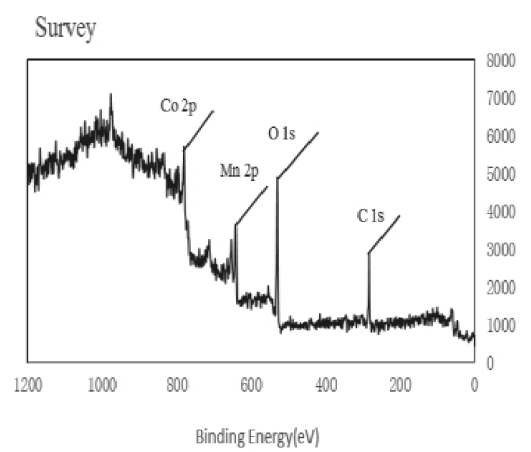

Mn2p Scan

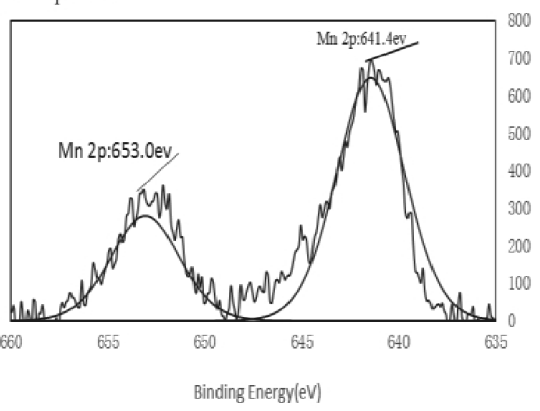

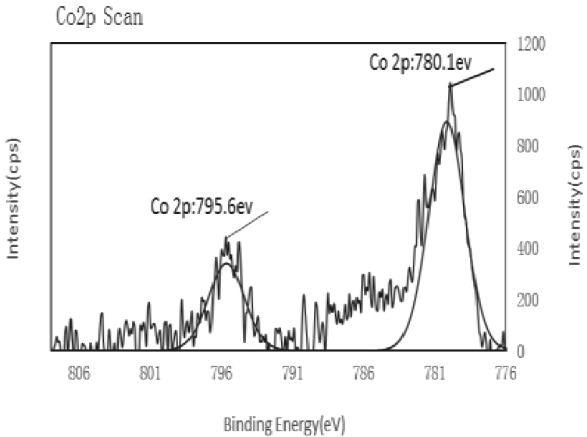

01s Scan

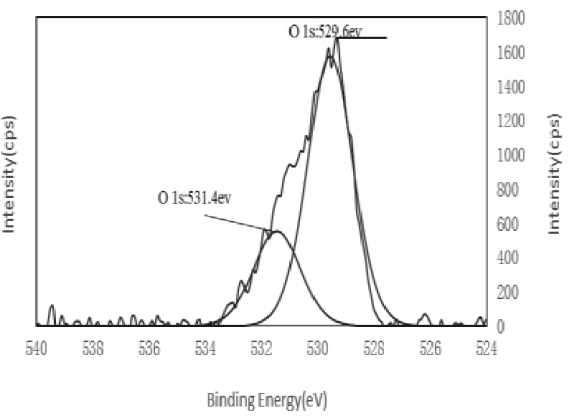

Fig. 9. XPS of Mn-CoO-supported catalyst by plasma modification.

is made. Fig. 8 is XPS spectra of C8. Fig. 8 shows that the peaks of manganese are two on the catalyst surface and there are two kinds of different valence states of oxide: $641.3 \mathrm{eV}$ is $\mathrm{Mn}^{4+}$ and $652.8 \mathrm{eV}$ is $\mathrm{Mn}^{3+}$. A lot of $\mathrm{Mn}^{4+}$ and a bit of $\mathrm{Mn}^{2+}$ are included in the catalyst, combined with XRD. Active metal oxide is generated on the surface more easily in the process of the catalyst by plasma roasting, and efficiency is beneficial. From the peak split of oxygen, it can be seen that the form of two kinds of oxygen exists: $529.7 \mathrm{eV}$ lattice oxygen and $531.6 \mathrm{eV}$ chemical adsorption of oxygen, and the number of lattice oxygen is obviously more than chemical oxygen adsorption state. It improves reactivity.

\section{XPS of Mn-CoO-Supported Catalyst by Plasma Modification}

Fig. 9 shows that the peaks of cobalt are two on the catalyst surface and there are two kinds of different valence states of oxide: $780.1 \mathrm{eV}$ is $\mathrm{CoO}$ and $795.6 \mathrm{eV}$ is $\mathrm{Co}_{3} \mathrm{O}_{4}$. Cobalt metal joined does not significantly improve manganese oxide, but the oxygen spectra is a great change and the amount of lattice oxygen increases obviously. Combined with the Fig. 5, it can be seen that the addition of $\mathrm{CoO}$ obviously improves denitration efficiency, and namely the lattice oxygen plays a positive role in the catalytic process. The increase of the lattice oxygen content makes that the number of holes and micro oxidation reaction increases, the formation energy that $\mathrm{NO}$ is oxidized and $\mathrm{NO}_{2}$ is reduced and the catalytic reaction happens more easily. When the reaction happens to a certain time, metal oxide loses the activity in the system, lattice oxygen loses the reaction of platform and denitration efficiency declines.

\section{SEM Characterization}

Fig. 10 is the result of SEM characterization of the catalysts. Fig. 10(b-d) and 10a) contrast and show that the grain of crystal appears obviously on the surface a)

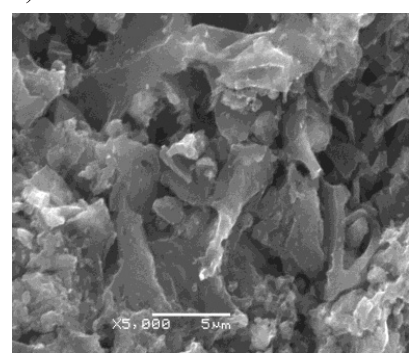

b)

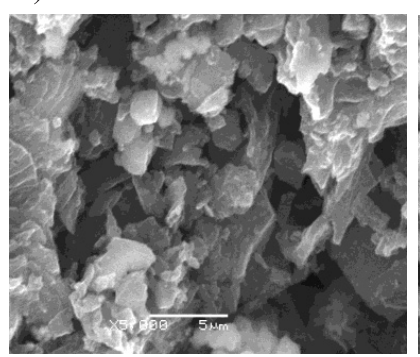

c)

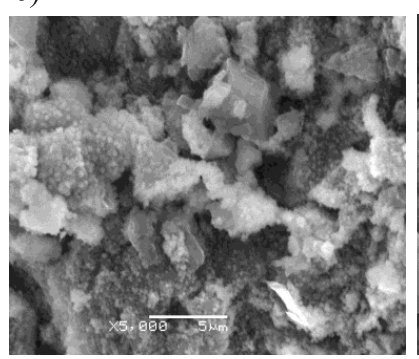

d)

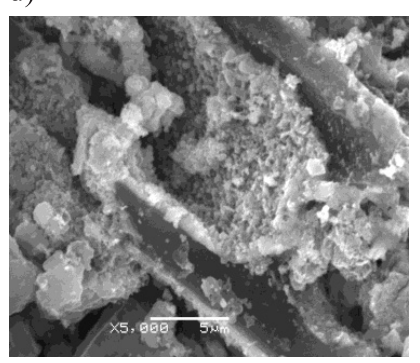

Fig. 10. SEM of catalysts: a) 750C pyrolysis coke, b) Conventional 8\% MnO-supported catalyst, c) C8, d) C8-10. 
Table 1. BET the results of specific surface area measurements.

\begin{tabular}{|c|c|}
\hline The type of catalyst & $\begin{array}{c}\text { Specific surface area } \\
\left(\mathrm{m}^{2} / \mathrm{g}\right)\end{array}$ \\
\hline $\begin{array}{c}\text { The conventional } 8 \% \\
\text { MnO/supported catalyst }\end{array}$ & 151.08931 \\
\hline $\mathrm{C} 8$ & 145.39247 \\
\hline
\end{tabular}

of the active component. And it can be seen that the catalysts of plasma modification compared with the pyrolysis coke, crystal particle of the former is more uniform and crystallinity of the former is poorer. The plasma modification combined muffle furnace roasting improves the uniformity and the dispersivity of active component, and it also improves reactivity. Comparing Fig. 10d) with Fig. 10c), we find obviously another kind of crystal in the Fig. 10d). Combined with the results of XRD and XPS, this kind of crystal particle is likely to be cobalt metal.

\section{BET Characterization}

Table 1 shows the specific surface area of the conventional 8\% MnO-supported catalyst and C8. The specific surface area of the catalyst prepared by plasma modification is similar to that of a conventional $8 \%$ $\mathrm{MnO}$-supported catalyst. However, combined with experimental data, it can be found that the denitration efficiency of $\mathrm{C} 8$ is significantly higher than that of the conventional $8 \%$ MnO-supported catalyst. We can conclude that there is no direct relationship between the change of the specific surface area of the catalyst and the activity of the catalyst.

\section{Conclusions}

The pyrolysis coke is the carrier, and the supported catalyst is prepared by using equal volume impregnation. By changing the powers and modification time of the plasma, the optimum power and the optimum modification time are explored. Then, under optimal plasma conditions, second kinds of metals are continued to be loaded. The effect of different metal loads on denitration efficiency is explored. The results showed:

1) The optimal modified power in a plasma system is $60 \mathrm{~W}$ and the best modified time in plasma system is 3 min.

2) After being modified by plasma, the denitration efficiency of catalysts are significantly higher than conventional calcination catalyst.

3) Among catalysts with different Co loadings (5\%, $8 \%, 10 \%), 8 \%$ Co loading had the best denitration efficiency.

4) $\mathrm{Mn}$-CoO-supported catalysts had certain $\mathrm{SO}_{2}$ resistance, and the denitration efficiency of $\mathrm{Mn}$ $\mathrm{CoO}$-supported catalyst> MnO-supported catalyst> unsupported catalyst.

\section{Acknowledgements}

Project 51704230 supported by National Natural Science Foundation of China; Financial support of this research was provided by Key Laboratory of Coal Resources Exploration and Comprehensive Utilization, Ministry of Land and Resources (Program No. KF2019-2) in P.R. China; The Project Supported by Natural Science Basic Research Plan in Shaanxi Province of China (Program No. 2018JM5048); Project 41602359 supported by National Natural Science Foundation of China; 2019 Scientific research plan by the geological research institute for coal green mining of Xi'an university of science and technology (Program No. MTy2019-16); 2017 Special Scientific Research Program of Shaanxi Provincial Education Department (17JK0507).

\section{Conflict of Interest}

The authors declare no conflict of interest.

\section{References}

1. SHI Y.L., CUI S.H., XU S., et al. Nitrogen oxide emission in energy consumption in China from a consumptionbased perspective. Acta Scientiae Circumstantiae, 34 (10), 2684, 2014.

2. GAO F.Y., TANG X.L., YI H.H., ZHAO S.Z., WANG J.E., SHI Y.R., MENG X.M. Novel Co-or Ni-Mn binary oxide catalysts with hydroxyl groups for $\mathrm{NH}_{3}-\mathrm{SCR}$ of $\mathrm{NOx}$ at low temperature. Applied Surface Science, 443 (15), 103, 2018.

3. YAO X.J., MA K.L., ZOU W.X., HE S.G., AN J.B., YANG F.M., DONG L. Influence of preparation methods on the physicochemical properties and catalytic performance of $\mathrm{MnOx}-\mathrm{CeO}_{2}$ catalysts for $\mathrm{NH}_{3}-\mathrm{SCR}$ at low temperature. Chinese Journal of Catalysis, 38 (01), 146, 2017.

4. FENG Q.W., ZHANG Y., WANG F.G., ZHU Y. Analysis on Operating Status of SCR Facilities in Active Coal-Fired Units. Electric Power, 50 (04), 157, 2017.

5. CHENG J.N., ZHANG X.L., YANG B.J., WU X.P., ZHANG H.J., ZHANG L.F. Preparation and NO catalytic oxidation activity of $\mathrm{Mn} / \mathrm{ZrO}$, catalyst. Acta Scientiae Circumstantiae, 34 (3), 620, 2014.

6. BI B.K., WANG X.M. New Desulfurization Process of DXY Selective Catalytic Oxidation. Chemical Fertilizer Industry, 43 (01), 41, 2016.

7. HU J.L., TANG X.L., YI H.H., LI K., SUN X. Recent Progress in Selective Catalytic Oxidation of Ammonia. Chemical World, 55 (05), 297, 2014.

8. YANG J.Q., MEI Y., WANG C., LONG G.H., LI S. Current status and trends on wet flue gas denitration technology. Chemical Industry and Engineering Progress, 36 (02), 695, 2017.

9. LIU L., ZHANG Y., XUE L., CHENG Y. Selective catalytic reduction of $\mathrm{NO}$ with $\mathrm{NH}_{3}$ over Mn/USY catalysts at low temperature. Chinese Journal of Environmental Engineering, 11 (07), 4112, 2017. 
10. HAJNAJAFI M., KHORSHIDI A., GILANI A.G., HEIDRI B. Catalytic degradation of malachite green in aqueous solution by porous manganese oxide octahedral molecular sieve (OMS-2) nanorods. Research on Chemical Intermediates, 44 (5), 3313, 2018.

11. YUE D.T., QIAN X.F., KAN M., FANG M.Y., JIA J.P., YANG X.D., ZHAO Y.X. A metal-free visible light active photo-electro-Fenton-like cell for organic pollutants degradation. Applied Catalysis B-Environmental, 229, 211, 2018.

12. LEE C.T., CHEN W.S., LEE H.Y. Quadruple GateEmbedded $T$ Structured GaN-Based Metal-OxideSemiconductor High-Electron Mobility Transistors. IEEE Journal of the Electron Devices Society, 6 (01), 63, 2018.

13. TASBIHI M., ACHARJYA A., THOMAS A., RELI M., AMBROZOVA N., KOCI K., SCHOMACKER R. Photocatalytic $\mathrm{CO}_{2}$ Reduction by Mesoporous Polymeric Carbon Nitride Photocatalysts. Journal of Nanoscience and Nanotechnology, 18 (8), 5636, 2018.

14. ZHAO T.W., YAO M.Y., FU K.L., CHENG G.G., YANG S., LI Y., CAI M. Review of study on catalysts for selective catalytic oxidation of $\mathrm{NO}$ in flue gas. Thermal Power Generation, 46 (04), 1, 2017.

15. ZHANG L., CHEN J.H., ZHANG L., LI Y.H., HE H., MA Z.H. Preparation of hydrogen-rich gas by heavy tar cracking with pyrolysis coke catalyst modified by plasma. Energy Sources, Part A: Recovery, Utilization, and Environmental Effects, 39 (15), 1647, 2017.

16. ZHANG L., LIU X., ZHANG L. Study on Desulfurization Performance of Modified Pyrolysis Char Loaded Catalyst. Coal Technology, 11 (35), 305, 2016.

17. LIANG X.Y., CHI J.J., YANG Z. The influence of the functional group on activated carbon for, acetone adsorption property by molecular simulation study. Microporous and Mesoporous Materials, 262, 77, 2018.

18. YANG Y.L., XU D.Y., CHAO C.Y., GAO M. Research advance review on supported Mn-based catalysts at lowtemperature selective catalytic reduction of NOx with $\mathrm{NH}_{3}$. Chemical Industry and Engineering Progress, 35 (04), 1094, 2016.

19. CHEN L., ZENG C., GUO X., MAO Y., ZHANG Y., ZHANG X., LI W., LONG Y., ZHU H. Gas evolution kinetics of two coal samples during rapid pyrolysis. Fuel processing technology, 91 (8), 848, 2010.

20. ZHANG L., JIA Y., ZHANG L., HE H.B., YANG C., LUO M., MIAO L.T. Preparation of soybean oil factory sludge catalyst by plasma and the kinetics of selective catalytic oxidation denitrification reaction. Journal of Cleaner Production, 217, 317, 2019. 
